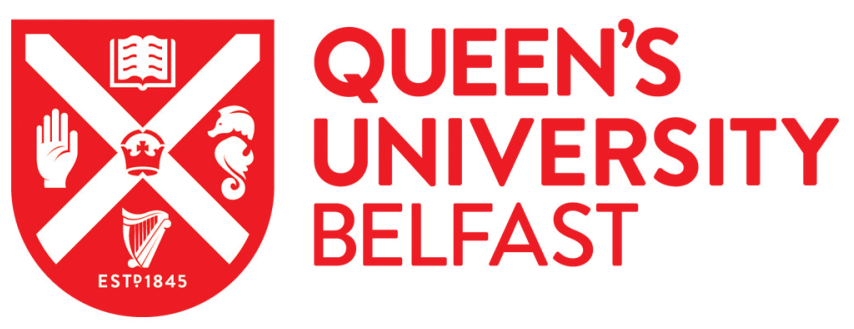

\title{
Medication use review in Qatar: Are community pharmacists prepared for the extended professional role?
}

\author{
Babiker, A. H., Carson, L., \& Awaisu, A. (2014). Medication use review in Qatar: Are community pharmacists \\ prepared for the extended professional role? International Journal of Clinical Pharmacy, 36(6), 1241-1250. \\ https://doi.org/10.1007/s11096-014-0025-8
}

\section{Published in:}

International Journal of Clinical Pharmacy

\section{Document Version:}

Peer reviewed version

Queen's University Belfast - Research Portal:

Link to publication record in Queen's University Belfast Research Portal

\section{Publisher rights}

(c) 2014 Springer International Publishing AG

The final publication is available at Springer via http://link.springer.com/article/10.1007\%2Fs11096-014-0025-8

\section{General rights}

Copyright for the publications made accessible via the Queen's University Belfast Research Portal is retained by the author(s) and / or other copyright owners and it is a condition of accessing these publications that users recognise and abide by the legal requirements associated with these rights.

Take down policy

The Research Portal is Queen's institutional repository that provides access to Queen's research output. Every effort has been made to ensure that content in the Research Portal does not infringe any person's rights, or applicable UK laws. If you discover content in the Research Portal that you believe breaches copyright or violates any law, please contact openaccess@qub.ac.uk. 


\title{
Medication use review in Qatar: Are community pharmacists prepared for the extended professional role?
}

\author{
A. H. Babiker \\ Pharmacy and Drug Control Department, Supreme Council of Health, P.O. Box 1919, Doha, Qatar \\ L. Carson \\ School of Pharmacy, Queen’s University Belfast, Belfast BT9 7BL, UK \\ A. Awaisu (\&) \\ Clinical Pharmacy and Practice Section, College of Pharmacy, Qatar University, P.O. Box 2713, Doha, Qatar \\ e-mail: aawaisu@qu.edu.qa
}

\begin{abstract}
Background The incidence of chronic illnesses is increasing globally. Non-adherence to medications and other medicationrelated problems are common among patients receiving long-term medications. Medication use review (MUR) is a service provision with an accredited pharmacist undertaking structured, adherence-centered reviews with patients receiving multiple medications. MUR services are not yet available in community pharmacies in Qatar. Objective The current study aims to evaluate com- munity pharmacists' knowledge, attitudes, and perception towards establishing MUR as an extended role in patient care. Setting Private community pharmacies in Qatar including chains and independent pharmacies. Methodology A cross-sectional survey using a self-administered ques- tionnaire was conducted among licensed community phar- macists from December 2012 to January 2013. Data analysis was conducted using descriptive and inferential statistics. Main outcome measures Knowledge, attitudes, and practices related to MUR concept and services. Results A total of 123 participants responded to the survey (response rate $56 \%$ ). The mean total knowledge score was

$71.4 \pm 14.7 \%$. An overwhelming proportion of the par- ticipants (97\%) were able to identify the scope of MUR in relation to chronic illnesses and at enhancing the quality of pharmaceutical care. Furthermore, $80 \%$ of the respondents were able to identify patients of priority for inclusion in an MUR program. However, only $43 \%$ of the participants knew that acute medical conditions were not the principal focus of an MUR service, while at least $97 \%$ acknowledged that the provision of MUR services is a great opportunity for an extended role of community pharmacists and that MUR makes excellent use of the pharmacist's professional skills in the community. The participants generally reported concerns about time, dedicated consultation area, and sup- port staff as significant barriers towards MUR implemen- tation. Conclusion This study suggests that community pharmacists in Qatar had sufficient knowledge about the concept of MUR and its scope, but there were still important deficiencies that warrant further education. The findings have important implications on policy and practice per- taining to the implementation of MUR as an extended role of pharmacists and as part of Qatar's National Health Strategy to move primary health care forward.
\end{abstract}

Impacts of the findings on pharmacy practice

- Further training and education through continuing professional development programs are warranted for community pharmacists in Qatar before implementing MUR service.

- In order to implement MUR services in Qatar, the service providers should be accredited based on com- petency standards and/or credentialing.

- Future studies should target pharmacists working in other primary health care sectors in order to determine their current knowledge, attitude, and practices and to determine their educational needs. 
the practice is still dominated by dispensing and sales of

The incidence of chronic diseases is increasing globally [1]. Non-adherence to medications, polypharmacy and other medication-related problems are common among patients receiving long-term medications for chronic illnesses [2, 3]. Medication use review (MUR) by pharmacists is becoming increasingly important globally as one of the strategies to prevent medication misadventures and a means to optimize the therapeutic outcomes of long-term medication use [4]. MUR is defined as a service provision with an accredited pharmacist undertaking structured adherence-centered reviews with patients on multiple medications (prescribed and non-prescribed), particularly those receiving medications for long-term conditions [5] in a private consultation area within the pharmacy, where patient and pharmacist are able to sit and communicate without interference or being overheard by others (pharmacy staff inclusive) [6]. Following the MUR, a report is provided to the patient and if necessary to the patient's general practitioner [7]. MUR gives an opportunity for patients to discuss their medications with a pharmacist, to increase understanding of how their medicines should be used and why they have been prescribed, as well as solving any problems they may be experiencing [8]. By educating patients about their medications, the MUR service ultimately helps patients improve compliance and concordance, and prevents adverse effects associated with polypharmacy. Although the MUR definition used in this paper is based on the UK model, MUR would be interpreted differently in different countries and the definition used here is just an example of such disparities.

The community pharmacy MUR service has been widely used in many developed countries around the world. MUR, as an advanced service, has been available in the United Kingdom since April 2005 [6, 8-10]. Similar medication reviews form part of community pharmacy services in Australia (through the Meds Check program introduced in 2007) [11, 12], the United States [13, 14] and in New Zealand in 2007 [15]. MUR is not yet established in community pharmacies in Qatar and little is known about the existence of the service in hospital and primary care settings.

Pharmacy practice in Qatar is rapidly evolving through important transformations and advancements. These can be illustrated in the development of cognitive and specialized hospital pharmacy services, pharmacy education, the country's health plans, and pharmacy leadership [16, 17]. Currently, the hospital pharmacy sector in Qatar provides clinical pharmacy services that were introduced in some government hospitals and facilities in 2006 [17]. Recently established government hospitals have been provided with automated dispensing devices and computer-aided drug distribution systems, sparing pharmacists' time for direct patient care activities and ensuring safe and rational medicines use [17]. However, in the private pharmacy sector, prescription and over-the-counter pharmaceutical products $[16,18,19]$. In general, pharmaceutical care, medicines management, and other advanced services are not commonplace in community pharmacies in Qatar $[16,18]$. Therefore, community pharmaceutical services in Qatar are predominated by traditional distribution of medicinal products. Similarly, this trend is reported in the private pharmacy sector by most countries in the region, and Qatar is no exception [18].

The Supreme Council of Health (SCH), which represents the highest health authority in Qatar, launched a national health agenda known as the National Health Strategy (NHS) 2011-2016 in April 2010 [20, 21]. This agenda sets out a strategic direction and key initiatives that the health sector will undertake from 2011 to 2016, in order to achieve the goals of the Qatar National Vision 2030 [22] and National Development Strategy (NDS) 2011-2016 [23]. The vision has stated clearly that all health services will be accessible to the entire population. There are seven goals within this strategy; the first is a comprehensive world-class healthcare system in which community pharmacy strategy is placed. One of the main deliverables and outputs in this strategy is an accreditation program for pharmacists and pharmacies to provide advanced and extended services such as MUR and health promotion.

To our knowledge, the current study is the first in Qatar to investigate community pharmacists' knowledge, attitude, and practice pertaining to MUR and in particular the potential impact of implementing MUR services as a means of improving the clinical outcomes and cost-effectiveness of prescribed medicines, and reducing waste.

\section{Aim of the study}

The purpose of this study was to: (1) assess the availability of facilities to support MUR implementation in community pharmacies in Qatar; (2) evaluate the pharmacist's knowledge and self-perceived competence in providing the MUR service; (3) explore their attitude and perceptions towards implementation of MUR; and (4) assess the practices of the community pharmacists pertaining to MUR. 
Ethical approval

Ethical approval for the study was obtained from Institutional Review Board (IRB) of the Qatar's SCH on 16 December 2012. The questionnaire was anonymous and no names or identity numbers were required.

\section{Method}

Study design and sample

A descriptive cross-sectional study using a self-administered questionnaire as a research instrument was conducted among community pharmacists in Qatar from December 2012 to January 2013. A sample of 220 pharmacists currently practicing in different cities and pharmacies was randomly selected to participate in the study. The sample size was estimated using the Raosoft ${ }^{\circledR}$ online calculator [24]. There were approximately 500 community pharmacists practicing in Qatar. In order to achieve a confidence level of $95 \%$ and a $5 \%$ margin of error, a minimum sample size of 180 was required. However, based on our previous experience with research culture and response rates in this country, we accounted for a non-response rate of $20 \%$. Therefore, a random sample of 220 community pharmacists was selected to participate in the study.

\section{Study setting}

The study involved pharmacists practicing in the private community pharmacy setting. Pharmacies in which respondents were employed can be categorized as either large multiples (pharmacy chain with greater than 10 outlets), medium multiples (pharmacy chain with 4-9 pharmacies), small multiples (pharmacy chain with 2-3 pharmacies), or single independent pharmacies.

\section{Eligibility criteria}

Inclusion criteria for potential respondents included: (1) being licensed as a practicing pharmacist in Qatar; (2) currently working as a community pharmacist and; (3) being working in a community pharmacy in Qatar for at least 12 months.

\section{Survey instrument development and implementation}

The questionnaire was developed with reference to the literature pertaining to MUR activities and MUR competencies [7, 9-12, 15], and after consultation with researchers and licensed community pharmacists. To improve face validity, the questionnaire was piloted on six community pharmacists (those who work in different community pharmacies with different general experiences and also with different nationalities and years of experiences in Qatarwho were eventually not included as study participants). Questions were designed to be comprehensive, and included four sections: demographics, knowledge, attitudes and practice, which were applicable to all respondents. The knowledge section consisted of 20 knowledge statements with true or false or unsure response options covering 4 areas: (1) MUR definition and conditions of implementation; (2) aims of the MUR service; (3) identification of patients for potential inclusion in an MUR program; and (4) important service elements in conducting an MUR. One point was awarded for each correct response and zero points for each incorrect or unsure response. The maximum possible score was 20 points (equivalent to $100 \%$ ). The attitude section of the survey tool consisted of 15 five-point Likert scaled attitudinal questions $(1=$ strongly disagree to $5=$ strongly agree). Attitudinal statements composed of three main areas: views about pharmacists' extended role of MUR service, effectiveness of the service, and implementation barriers. While in the last section, the questionnaire included 15 Likert scaled practice and availability of facilities statements $(1=$ strongly disagree to $5=$ strongly agree). These statements portrayed the willingness to provide MUR services within daily practice activities, time allocation to provide these services, availability of information technology (IT), administrative support, and development of structured training programs before commencing MUR services including a responsible body for accreditation of MUR services provision.

The survey was launched by distributing questionnaires through personal visits to pharmacies in December 2012, along with an explanatory statement to inform each participant about the purpose and objectives of the study, as well as the confidentiality of the survey results and that no efforts would be made to track individual responses.

\section{Statistical analysis}

The collected data from returned questionnaires were entered into IBM Statistical Package for Social Science (IBM SPSS $^{\circledR}$ Statistics) version 20 for analysis. Both descriptive and inferential statistics were used for the analysis. Community pharmacists' demographic information and professional characteristics were calculated as frequencies and percentages (i.e. proportions) since they were all categorical variables. Proportions were also used to portray the respondents' knowledge, attitudes and practice on MUR. Respondents' total knowledge score was further calculated as mean $\pm \mathrm{SD}$. Independent $t$ test and One-way ANOVA test were used to determine the effect of 
Table 1 Demographic and professional characteristics of community pharmacists in Qatar $(\mathrm{n}=116)$

\begin{tabular}{|c|c|}
\hline Characteristics & Proportion, n (\%) \\
\hline \multicolumn{2}{|l|}{ Gender } \\
\hline Male & $74(63.8)$ \\
\hline Female & $42(36.2)$ \\
\hline \multicolumn{2}{|l|}{ Nationality } \\
\hline Indian & $56(48.3)$ \\
\hline Egyptian & $31(26.7)$ \\
\hline Filipino & $18(15.5)$ \\
\hline Syrian & $3(2.6)$ \\
\hline Palestinian & $2(1.7)$ \\
\hline Others & $6(5.2)$ \\
\hline \multicolumn{2}{|l|}{ Age category (years) } \\
\hline $25-34$ & $70(60.3)$ \\
\hline $35-44$ & $38(32.8)$ \\
\hline $45-54$ & $8(6.9)$ \\
\hline \multicolumn{2}{|l|}{ Highest pharmacy degree obtained } \\
\hline BSc & $112(96.6)$ \\
\hline MSc & $4(3.4)$ \\
\hline \multicolumn{2}{|l|}{ Country of highest degree } \\
\hline India & $58(50)$ \\
\hline Egypt & $31(26.7)$ \\
\hline Philippines & $18(15.5)$ \\
\hline Jordan & $2(1.7)$ \\
\hline Pakistan & $2(1.7)$ \\
\hline Others & $5(4.4)$ \\
\hline \multicolumn{2}{|l|}{ Years of experience* } \\
\hline$\Longrightarrow 2$ & $4(3.5)$ \\
\hline $2-5$ & $26(23.0)$ \\
\hline $6-10$ & 36 (31.9) \\
\hline 11-15 & $32(28.3)$ \\
\hline $16-20$ & $12(10.6)$ \\
\hline$>21$ & $3(2.7)$ \\
\hline \multicolumn{2}{|l|}{ Years of community practice in Qatar } \\
\hline$<2$ & $33(28.4)$ \\
\hline $2-5$ & $40(34.5)$ \\
\hline $6-10$ & $26(22.4)$ \\
\hline $11-15$ & $14(12.1)$ \\
\hline $16-20$ & $3(2.6)$ \\
\hline \multicolumn{2}{|l|}{ Weekly working hours } \\
\hline$<10$ & $7(6.0)$ \\
\hline $10-19$ & $1(0.9)$ \\
\hline $20-29$ & $3(2.6)$ \\
\hline $30-39$ & $5(4.3)$ \\
\hline $\mathrm{C} 40$ & $100(86.2)$ \\
\hline \multicolumn{2}{|l|}{ Attitude towards practice change* } \\
\hline Willing to take risks & $38(35.2)$ \\
\hline Serve as a role model & $44(40.7)$ \\
\hline Deliberate before adopting new changes & $20(18.5)$ \\
\hline
\end{tabular}

Table 1 continued

Characteristics

Proportion, n (\%)

Tend to change once most peers have done so

$4(3.7)$

Resist new ways of working

$2(1.9)$

* Some missing data

sociodemographic and professional characteristics on pharmacists' MUR knowledge. The level of significance was set a priori at $\mathrm{p}<0.05$.

Results

Demographic and professional characteristics of the respondents

One hundred twenty-three community pharmacists from different pharmacy ownership throughout the State of Qatar completed the survey (response rate was $56 \%$ ). Of the 123 returned surveys, only 116 were useable; surveys in which the respondents skipped 5 or more questions were excluded to preserve the data quality.

The majority of the respondents (74/116; $63.8 \%)$ were male (Table 1). Half (58/116) of the respondents obtained their highest pharmacy degree from India, followed by Egypt (31/116; $26.7 \%)$, Philippines (18/116; $15.5 \%$ ), and the rest of the respondents were from other countries. The vast majority of the participants (112/116; $96.6 \%)$ pos- sessed BSc degree as the highest pharmacy degree. The majority (83.2\%) of the pharmacists who responded to the survey had general pharmacy experience between 2 and

15 years. Other details on the sociodemographic and professional characteristics of the respondents are provided in Table 1.

Community pharmacists' knowledge

towards medication use review

Table 2 presents the respondents' knowledge on different aspects of MUR. Approximately, $93.1 \%$ (108/116) of the respondents knew the general definition of MUR. In addition to that, the majority of the respondents (96.6\%; 112/116) were able to identify the scope of MUR services pertaining to chronic diseases such as diabetes, asthma and hypertension. However, only $43.4 \%$ (49/113) knew that MUR services are not usually provided for acute and critical conditions such as acute myocardial infarction and acute decompensated heart failure.

Approximately $96.6 \%(112 / 116)$ of the community pharmacists surveyed had correctly answered the question that "MUR service is aimed at enhancing the quality use of 
Table 2 Knowledge of medication use review among community pharmacists in Qatar $(n=116)$

\begin{tabular}{|c|c|c|c|c|}
\hline \multicolumn{2}{|c|}{ Knowledge items } & \multicolumn{3}{|l|}{ N (\%) } \\
\hline & & \multirow[t]{2}{*}{ True } & \multirow[t]{2}{*}{ False } & \multirow[t]{2}{*}{ Not sure } \\
\hline Gen & l MUR definition and condition of implementation & & & \\
\hline 1 & $\begin{array}{l}\text { MUR is a service that involves an accredited pharmacist undertaking structured } \\
\text { concordance centered reviews with patients on multiple medicines, particularly } \\
\text { those receiving medicines for long-term conditions }\end{array}$ & $108(93.1)$ & $2(1.7)$ & $6(5.2)$ \\
\hline 2 & MUR is more important for chronic diseases such as diabetes, asthma, and hypertension & $112(96.6)$ & $3(2.6)$ & $1(0.9)$ \\
\hline 3 & $\begin{array}{l}\text { MUR services are provided for in-patients who present with acute or critical } \\
\text { condition e.g. acute myocardial infarction (MI)* }\end{array}$ & $49(43.4)$ & 36 (31.9) & $28(24.8)$ \\
\hline \multicolumn{5}{|c|}{ Aims of MUR services } \\
\hline 4 & $\begin{array}{l}\text { MUR is aimed at enhancing the quality use of medicines and reducing the number } \\
\text { of adverse drug events }\end{array}$ & $112(96.6)$ & $2(1.7)$ & $2(1.7)$ \\
\hline 5 & $\begin{array}{l}\text { MUR is aimed to identify problems that the patients may be experiencing with their } \\
\text { disease states }\end{array}$ & $91(78.4)$ & $13(11.2)$ & $12(10.3)$ \\
\hline 6 & MUR is aimed to help patients become experts on medications* & $74(64.3)$ & 19 (16.5) & $22(19.1)$ \\
\hline 7 & $\begin{array}{l}\text { MUR is aimed to help in improving the effective use of medicines by patients including } \\
\text { learning about how the medicines affect their diseases }\end{array}$ & $103(88.8)$ & $3(2.6)$ & $10(8.6)$ \\
\hline \multicolumn{5}{|c|}{ Identified patients' priority for potential inclusion in an MUR program } \\
\hline 8 & $\begin{array}{l}\text { Taking more than five regular medicines, } 12 \text { doses of medicine per day or being } \\
\text { treated for three medical conditions }\end{array}$ & $100(86.2)$ & $6(5.2)$ & $10(8.6)$ \\
\hline 9 & Discharged from hospital in last 4 weeks* & $63(54.8)$ & $21(18.3)$ & $31(27.0)$ \\
\hline 10 & Medication regimen changed in last 3 months* & $89(77.4)$ & $8(7.0)$ & $18(15.7)$ \\
\hline 11 & $\begin{array}{l}\text { Taking a medicine with narrow therapeutic index or requiring therapeutic drug } \\
\text { monitoring }\end{array}$ & $96(82.8)$ & $8(6.9)$ & $12(10.3)$ \\
\hline 12 & Symptoms suggestive of an adverse drug reaction (ADR) symptoms* & $99(86.1)$ & $6(5.2)$ & $10(8.7)$ \\
\hline 13 & Suspected non-compliance to multiple medications* & $91(79.8)$ & $9(7.9)$ & $14(12.3)$ \\
\hline 14 & $\begin{array}{l}\text { Problems managing medication-related to therapeutic devices such as asthma } \\
\text { inhalers and insulin pen }\end{array}$ & $94(81.0)$ & $11(9.5)$ & $11(9.5)$ \\
\hline 15 & Dexterity problems e.g. impaired sight* & $58(50.4)$ & $23(20.0)$ & $34(29.6)$ \\
\hline 16 & Risk due to language/literacy difficulties & 66 (56.9) & $23(19.8)$ & $27(23.3)$ \\
\hline \multicolumn{5}{|c|}{ Important service elements in conducting MUR } \\
\hline 17 & Gathering relevant information from the patient or the patient's caregiver & $106(91.4)$ & $4(3.4)$ & $6(5.2)$ \\
\hline 18 & $\begin{array}{l}\text { Reviewing and discussing the patient's use of all medicines } \\
\text { and medication/monitoring devices }\end{array}$ & $107(92.2)$ & $2(1.7)$ & $7(6.0)$ \\
\hline 19 & Developing action plan including GP follow up* & $84(73.0)$ & $7(6.1)$ & $24(20.9)$ \\
\hline 20 & Arranging agreed follow-up actions & $90(77.6)$ & $8(6.9)$ & 18 (15.5) \\
\hline
\end{tabular}

* Some missing data

medicines and reducing the number of adverse drug events indices (82.8\%; 96/116), and symptoms suggestive of experienced by the patients”. Similarly, $64.3 \%$ (74/115) of the participants incorrectly assumed that MUR is aimed to help patients become medication therapy experts.

The majority of the respondents (86.2\%; 100/116) knew that MUR should be implemented for patients who are "taking more than five regular medicines, 12 doses of medicines per day or being treated for three medical conditions". Similarly, a large proportion of the respondents correctly identified the following eligibility criteria for MUR program: problems managing the usage of therapeutic devices such as asthma inhalers and insulin pens (81\%; 94/116), taking medicines with narrow therapeutic 
ADRs (86.1 \%; 99/115). Despite the large proportion of the surveyed pharmacists' knowledge regarding the potential inclusion criteria to MUR service, a non-negligible percentage (27\%) were unsure whether these services could be implemented for those who were discharged from hospital in the last 4 weeks.

At least three-quarters of the respondents were aware that elements such as gathering relevant information about patient history, reviewing the patient use of medicines and monitoring devices, developing a written action plan and follow up actions, are important service elements in conducting a MUR (Table 2).

Overall, the highest total knowledge score among the community pharmacists surveyed was found to be $95 \%$ 
Table 3 The influence of Qatar community pharmacists' characteristics on their knowledge about medication use review $(\mathrm{n}=116)$

\begin{tabular}{|c|c|c|}
\hline Characteristics & $\begin{array}{l}\text { Mean } \\
\text { knowledge } \\
\text { score (SD) }\end{array}$ & $\mathrm{p}$ value ${ }^{\S}$ \\
\hline Overall mean knowledge score (range) & & - \\
\hline \multicolumn{3}{|l|}{$71.4 \pm 14.7 \%(80 \%)$} \\
\hline Gender & & $0.531 *(\mathrm{NS})$ \\
\hline Male & $72.0(13.8)$ & \\
\hline Female & $70.2(16.3)$ & \\
\hline Age category (years) & & 0.777 (NS) \\
\hline $25-34$ & $70.6(12.4)$ & \\
\hline $35-44$ & $72.8(17.8)$ & \\
\hline $45-54$ & $71.3(18.7)$ & \\
\hline Highest pharmacy degree obtained & & 0.380 (NS) \\
\hline BSc & $71.6(14.9)$ & \\
\hline MSc & $65.0(7.1)$ & \\
\hline Years of experience & & 0.133 (NS) \\
\hline$\checkmark 2$ & $66.3(8.5)$ & \\
\hline $2-5$ & $67.7(13.7)$ & \\
\hline $6-10$ & $69.7(15.1)$ & \\
\hline $11-15$ & $75.9(11.6)$ & \\
\hline $16-20$ & $67.5(22.1)$ & \\
\hline Г21 & $83.3(2.9)$ & \\
\hline Years of community practice in Qatar & & 0.135 (NS) \\
\hline$\checkmark 2$ & $69.4(11.0)$ & \\
\hline $2-5$ & $68.4(17.4)$ & \\
\hline $6-10$ & $77.5(12.9)$ & \\
\hline $11-15$ & $73.2(14.6)$ & \\
\hline $16-20$ & $71.7(18.9)$ & \\
\hline Weekly working hours & & 0.868 (NS) \\
\hline$\checkmark 10$ & $69.3(18.4)$ & \\
\hline $10-19$ & $60.0(-)$ & \\
\hline $20-29$ & $76.7(7.6)$ & \\
\hline 30-39 & $74.0(6.5)$ & \\
\hline $\mathrm{C} 40$ & $71.4(15.0)$ & \\
\hline Attitude towards practice change & & $0.032(\mathrm{~S})$ \\
\hline Willing to take risks & $70.0(14.1)$ & \\
\hline Serve as a role model & $76.1(10.4)$ & \\
\hline Deliberate before adopting new changes & $65.8(20.9)$ & \\
\hline Tend to change once most peers have done so & $67.5(17.1)$ & \\
\hline Resist new ways of working & $55.0(21.2)$ & \\
\hline
\end{tabular}

$\S \mathrm{p}$ values were calculated using One-way ANOVA test

* p values was calculated using independent $t$ test

S significant, NS non-significant

and the minimum was $15 \%$. The mean total knowledge score $( \pm \mathrm{SD})$ was $71.4 \pm 14.7 \%$ (Table 3 ). Further analyses were conducted to determine the influence of the pharmacists' demographic and professional characteristics on their knowledge of MUR (Table 3). Gender, age, highest pharmacy degree obtained, years of experience, and weekly working hours, all had no significant effect on the knowledge ( $\mathbf{p}$ [0.05). However, attitude towards where pharmacists who aspired to serve as role models had the highest level of knowledge, while those who described

themselves as resistant to new ways of working had the least knowledge (76.1 vs. 55.0, respectively; $\mathrm{p}=0.032$ ).

practice change had significant effect on the knowledge; 
Community pharmacists' attitudes towards medication use review

The respondents generally exhibited positive attitudes toward MUR service provision (Table 4). Information collected regarding the attitudinal statements was in almost universal acknowledgement that: MUR service is a great opportunity for an extended role of community pharmacists (96.5\%; 112/116); MUR makes an excellent use of the pharmacist's professional skills in the community (95.7 \%; 110/115); through the MUR service, pharmacists' understanding of their patients views about medicines will be enhanced (91.2\%; 104/114). The majority (87.9\%; 102/116) of the respondents disagreed with the statement that MUR service was a waste of the community pharmacist's time. In addition, this was supported also by a high expression of disagreement (83.6 \%; 97/116) with the statement that community pharmacists would not like to see more advanced services introduced in the future.

Furthermore, there was a high expression of disagreement with the suggestion that MURs would not improve patient compliance (81 \%; 94/116) or cost-effectiveness of prescribed medication $(66.1 \%$; 76/115). Less than half (41.7 \%; 48/115) of the surveyed pharmacists believed that a lack of access to medical records reduces the benefits of MUR services, and a sizeable proportion (59.5 \%; 69/116) believed that patients would want a community pharmacist to review their medications. More than half (57.7\%; 67/116) of the respondents felt that there was enough time to carry out MUR services. However, there was no consensus as to the availability of adequate supporting staff to provide MUR services. Three-quarters of the pharmacists agreed to conduct MUR services if they had a suitable consultation area. In contrast, only $40.5 \%$ (47/116) of the respondents were willing to provide more MURs if provided with a reasonable financial incentive.

Practice and availability of facilities related to medication use review

Most (87 \%; 100/115) of the surveyed pharmacists were willing to provide MUR services in spite of their engagement with other daily practice activities (Table 5). Regarding availability of facilities to support MUR services establishment and continuous provision in community pharmacies, it was found that less than a quarter (23.3\%; 27/116) of the surveyed pharmacists agreed that there was sufficient IT support. 
Table 4 Attitude towards medication use review and its implementation among Qatar community pharmacists $(\mathrm{n}=116)$

\begin{tabular}{|c|c|c|c|c|c|c|}
\hline \multirow{2}{*}{\multicolumn{2}{|c|}{ Attitudinal items }} & \multicolumn{5}{|l|}{ N (\%) } \\
\hline & & $\begin{array}{l}\text { Strongly } \\
\text { agree }\end{array}$ & Agree & Neutral & Disagree & $\begin{array}{l}\text { Strongly } \\
\text { disagree }\end{array}$ \\
\hline \multicolumn{7}{|c|}{ Attitudes towards MUR as an extended role } \\
\hline 1 & $\begin{array}{l}\text { The MUR service is a great opportunity for an extended role for community } \\
\text { pharmacists }\end{array}$ & $65(56.0)$ & $47(40.5)$ & $4(3.4)$ & $0(0)$ & $0(0)$ \\
\hline 2 & $\begin{array}{l}\text { MUR makes excellent use of the pharmacist's professional skills in the } \\
\text { community* }\end{array}$ & $70(60.9)$ & $40(34.8)$ & $5(4.3)$ & $0(0)$ & $0(0)$ \\
\hline 3 & $\begin{array}{l}\text { Pharmacists understanding of their patients views about medicines will be } \\
\text { enhanced by the MURs* }\end{array}$ & $51(44.7)$ & $53(46.5)$ & $7(6.1)$ & $2(1.8)$ & $1(0.9)$ \\
\hline 4 & The MUR service is a waste of the pharmacist's time & $2(1.7)$ & $4(3.4)$ & $8(6.9)$ & $52(44.8)$ & $50(43.1)$ \\
\hline 5 & I would not like to see more of these new services in the future & $6(5.2)$ & $7(6)$ & $6(5.2)$ & $49(42.2)$ & $48(41.4)$ \\
\hline \multicolumn{7}{|c|}{ Attitudes towards the perceived effectiveness of MUR to patients } \\
\hline 6 & The MUR service will improve poor or ineffective use of the patient's medicine & $49(42.2)$ & $51(44.0)$ & $6(5.2)$ & $5(4.3)$ & $5(4.3)$ \\
\hline 7 & The MUR service will not improve patient compliance to drug therapy & $2(1.7)$ & $5(4.3)$ & $15(12.9)$ & $63(54.3)$ & $31(26.7)$ \\
\hline 8 & $\begin{array}{l}\text { The MUR service will not improve the cost-effectiveness of prescribed } \\
\text { medication* }\end{array}$ & $1(0.9)$ & $8(7.0)$ & $30(26.1)$ & $49(42.6)$ & $27(23.5)$ \\
\hline 9 & $\begin{array}{l}\text { Without access to medical notes, patients will not see the full benefit from the } \\
\text { review* }\end{array}$ & $5(4.3)$ & $43(37.4)$ & $34(29.6)$ & $26(22.6)$ & $7(6.1)$ \\
\hline 10 & $\begin{array}{l}\text { In my opinion, patients simply may not want the pharmacist to review their } \\
\text { medications }\end{array}$ & $3(2.6)$ & $14(12.1)$ & $30(25.9)$ & $50(43.1)$ & $19(16.4)$ \\
\hline \multicolumn{7}{|c|}{ Attitudes towards perceived barriers } \\
\hline 11 & I simply do not have enough time to carry out MUR & $4(3.4)$ & $18(15.5)$ & $27(23.3)$ & $47(40.5)$ & $20(17.2)$ \\
\hline 12 & I have enough supporting staff to enable me to conduct MURs to my satisfaction & $11(9.5)$ & $30(25.9)$ & $41(35.3)$ & $30(25.9)$ & $4(3.4)$ \\
\hline 13 & I would conduct more MURs if I had a reasonable financial incentive & $19(16.4)$ & $28(24.1)$ & $42(36.2)$ & $21(18.1)$ & $6(5.2)$ \\
\hline 14 & I could conduct many MURs if I had a suitable consultation area & $27(23.3)$ & $61(52.6)$ & $23(19.8)$ & $5(4.3)$ & $0(0)$ \\
\hline 15 & I think GPs see MURs as a valuable contribution to patient care & $31(26.7)$ & $49(42.2)$ & $28(24.1)$ & $4(3.4)$ & $4(3.4)$ \\
\hline
\end{tabular}

* Some missing data

A large proportion of the participants (94.8 \%; 109/115) agreed that training programs should be conducted under the control of the SCH for the purpose of education and orientation of community pharmacists before implementing MUR services in Qatar. Moreover, there was universal agreement $(95.6 \%$; 111/116) that the training programs should involve the academia (universities) along with $\mathrm{SCH}$. Remuneration is a major issue impinging on community pharmacist's participation in MUR services. As a result, three-quarters of the respondents indicated that the government should reimburse the MUR service provider, while only $23.3 \%(27 / 116)$ believe that patients should be charged for MUR services.

\section{Discussion}

Although MUR as an advanced pharmacy service, is yet to be implemented in community pharmacies in Qatar as an additional service alongside the traditional dispensing services, community pharmacists have demonstrated willing- ness to be involved in such a service for the purpose of 
improving patient care. There is a great incentive for the implementation of MUR in Qatar, as considerable efforts to raise the pharmacist's public image and professional role are underway. This effort should demonstrate the potential benefits of extending pharmacists' contributions to pharmaceutical care beyond accurate dispensing and the provision of basic counseling.

The pharmacist guidelines for the provision of Home Medication Review (HMR) services, published by Pharmaceutical Society of Australia in October 2011 [25], identified patients who could benefit from HMR including those who are at risk of medications misadventure due to multiple conditions, co-morbidities, discharge from a hospital in the past 4 weeks, and those patients who self-manage their own medications and are at risk due to literacy or language difficulties and those with dexterity problems (e.g. impaired vision and cognitive deteriorations). This survey has shown that non-negligible proportions (23-30\%) of the respondents were unsure as to whether these services could be implemented for those patients who were discharged from hospital within the past 4 weeks, and whether dexterity problems and languages/literacy difficulties should also be 
Table 5 Future practice of medication use review and availability of facilities in Qatar community pharmacies

\begin{tabular}{|c|c|c|c|c|c|c|}
\hline & \multicolumn{5}{|l|}{ N (\%) } \\
\hline \multicolumn{2}{|c|}{ Survey items } & \multirow{2}{*}{$\begin{array}{l}\begin{array}{l}\text { Strongly } \\
\text { agree }\end{array} \\
34(29.6)\end{array}$} & \multirow{2}{*}{$\begin{array}{l}\text { Agree } \\
66 \text { (57.4) }\end{array}$} & \multirow{2}{*}{$\begin{array}{c}\text { Neutral } \\
12(10.4)\end{array}$} & \multirow{2}{*}{$\begin{array}{c}\text { Disagree } \\
3(2.6)\end{array}$} & \multirow{2}{*}{$\begin{array}{l}\begin{array}{l}\text { Strongly } \\
\text { disagree }\end{array} \\
0(0)\end{array}$} \\
\hline 1 & $\begin{array}{l}\text { I have the willingness to provide MUR services within my daily practice } \\
\text { activities* }\end{array}$ & & & & & \\
\hline 2 & $\begin{array}{l}\text { I have sufficient time within my daily work to provide MUR services for more } \\
\text { than } 1 \text { day a week }\end{array}$ & $13(11.2)$ & $43(37.1)$ & $35(30.2)$ & $23(19.8)$ & $2(1.7)$ \\
\hline 3 & $\begin{array}{l}\text { I have sufficient IT support to provide MUR services in my community } \\
\text { pharmacy }\end{array}$ & $7(6.0)$ & $20(17.2)$ & $41(35.3)$ & $43(37.1)$ & $5(4.3)$ \\
\hline 4 & I have sufficient administrative support to provide MUR services & $5(4.3)$ & $35(30.2)$ & $43(37.1)$ & $30(25.9$ & $3(2.6)$ \\
\hline 5 & Training programs to be done by $\mathrm{SCH}^{*}$ & $66(57.4)$ & $43(37.4)$ & $6(5.2)$ & $0(0)$ & $0(0)$ \\
\hline 6 & $\begin{array}{l}\text { Involvement of Universities along with SCH for orientation and education of } \\
\text { community pharmacist before implementing MUR services }\end{array}$ & $62(53.4)$ & $49(42.2)$ & $5(4.3)$ & $0(0)$ & $0(0)$ \\
\hline 7 & I already have sufficient training to provide MUR services & $6(5.2)$ & $13(11.2)$ & $43(37.1)$ & $50(43.1)$ & $4(3.4)$ \\
\hline 8 & I have enough experience of being involved in MUR & $12(10.3)$ & $31(26.7)$ & $36(31.0)$ & $36(31.0)$ & $1(0.9)$ \\
\hline 9 & Already providing MUR services in my community pharmacy* & $8(7.0)$ & $27(23.5)$ & 39 (33.9) & $37(32.2)$ & $4(3.5)$ \\
\hline 10 & Accreditation of community pharmacy and pharmacists* & $40(35.1)$ & $53(46.5)$ & $18(15.8)$ & $1(0.9)$ & $2(1.8)$ \\
\hline 11 & $\begin{array}{l}\text { Community pharmacist's accreditation should be obtained from SCH or an } \\
\text { academic institution }\end{array}$ & $43(37.1)$ & $55(47.4)$ & $14(12.1)$ & $3(2.6)$ & $1(0.9)$ \\
\hline 12 & Government should reimburse the MUR service provider & $34(29.3)$ & $53(45.7)$ & $26(22.4)$ & $3(2.6)$ & $0(0)$ \\
\hline 13 & Insurance company should reimburse the MUR service provider & $27(23.3)$ & $46(39.7)$ & $35(30.2)$ & $7(6.0)$ & $1(0.9)$ \\
\hline 14 & Patient should also be charged for MUR services & $5(4.3)$ & $22(19.0)$ & $31(26.7)$ & $43(37.1)$ & $15(12.9)$ \\
\hline 15 & Availability of a screened area in the community pharmacy for MUR services & $9(7.8)$ & $20(17.2)$ & $22(19.0)$ & 46 (39.7) & 19 (16.4) \\
\hline
\end{tabular}

* Some missing data

considered. These points of uncertainty call for stipulation of mandatory education and training programs before commencing MUR services in Qatar.

The respondents acknowledged that the provision of MUR services is a great opportunity for an extended role of community pharmacist and that MUR makes an excellent use of the pharmacist's professional skills in the community. This is in line with what has been reported among community pharmacists in the UK on moving their professional skills towards best practices and new extended roles [7]. Furthermore, GP's acknowledgement of pharmacists' skill and knowledge, with regard to medicines and the potential benefit of extending new services were found by other studies [26, 27].

Since April 2005, at the time of implementation of MUR services in community pharmacies in the UK [9] and to date, there were many successful attempts around the globe to implement these services, such as in New Zealand [15], for the purpose of improving patients' use of medicine, patient compliance and cost-effectiveness of prescribed medications [28, 29]. A significant number of surveyed pharmacists in this study were found to agree with these benefits. However, lack of access to medical records reduced the benefits of MUR services. 
This study highlights some of the barriers perceived by the pharmacists affecting their involvement in the future provision of MUR services in Qatar. The majority were willing to conduct these services once a suitable consultation area was available, and interestingly they were willing to provide the service without consideration of the amount of incentive expected through remuneration. All the previous attitudinal points need to be investigated or further studied after implementation of the MUR program, to compare the current theoretical data with a practical dataset. On the other hand, once these highlighted barriers are addressed, the workload of the community pharmacists may increase, and this may present as a barrier in the future [30]. Many of the surveyed pharmacists thought that GPs would consider MURs as a valuable contribution to patient care in Qatar. In agreement with the findings from other studies, GPs expressed a positive attitude towards pharmacists expanding their roles of service if a good working relationship was established [27]. In addition, closer collaboration between GPs and pharmacists could potentially improve patients' use of medicines [31]. However, some previous reports have highlighted some isolated incidences of reluctance or slow GP referral [15].

This survey revealed that less than half of the surveyed pharmacists agreed that there was sufficient IT support and 
administrative support for these services. These findings are related to the availability of facilities to support MUR establishment and continuous provision in community pharmacies. Hence great efforts need to be made to ensure that the support and readiness for MUR provision are in place before implementation. This is supported by the Qatar NHS goals, to improve healthcare in Qatar to the level of comprehensive world-class healthcare system, whose services are accessible to the whole population. This is in line with achieving the goal of the Qatar National Vision 2030 [22] and the NDS 2011-16 [23, 32].

A large proportion of the participants indicated that training and education programs should be conducted for community pharmacists under the control of SCH, with the involvement of academia, before implementing MUR services. This would be a prerequisite for the accreditation of pharmacists who are willing to participate in an MUR services program, as per the requirements of other countries offering MUR in the community pharmacy setting [7, 9, 11, 15].

This study has some important limitations that are inherent to most survey-type studies. First, the response rate, although relatively high compared to similar studies conducted in Qatar, is an issue of concern. Therefore, the results may not be generalized and representative of all community pharmacists in Qatar, but did provide an indication of the attitude of a reasonable number of community pharmacists in the country. Second, the questionnaire was distributed using hardcopy, subjecting the responses to bias due to possibility of communication among the respondents. Third, social desirability bias might have influenced how the pharmacists responded to the attitudinal items. Lastly, it is worthwhile to stress that the MUR definition used here originates from the UK and the survey tool looked into the implementation of some specific models of MUR. Future studies should investigate the perceptions of the pharmacists towards a model that is customized to Qatar.

\section{Conclusions}

Pharmacists in Qatar have sufficient knowledge regarding the concept of MUR and its scope, despite some areas of deficiencies and misconception about the practice. Pharmacists need to be educated and trained about the potential benefits of MUR in improving the overall outcome of healthcare. This calls for a systematic and structured training program encompassing the core elements of MUR services and processes prior to implementation. This study has documented an apparent lack of availability of facilities and environment for the provision of MUR, such as dedi- cated consultation area and IT support system. This warrants advocacy by pharmacy owners and regulators for improvement of facilities.

The current findings have important implications on the implementation of MUR services as an extended role for pharmacists and as part of Qatar's NHS 2011-2016 agenda to move primary health care forward. As per best practices and international standards, mandatory accreditation of any pharmacist who plans to provide such extended services is warranted.

Acknowledgments The authors would like to thank all community pharmacists who voluntarily participated in the study.

Funding This study received no funding from any public or private entity. The statements made herein are solely the responsibility of the authors.

Conflicts of interest The authors have no competing interests to declare.

\section{References}

1. Heneghan C, Blacklock C, Perera R, Davis R, Banerjee A, Gill P, et al. Evidence for non-communicable diseases: analysis of Cochrane reviews and randomised trials by World Bank classification. BMJ Open. 2013;3:e003298.

2. Marcum ZA, Zheng Y, Perera S, Strotmeyer E, Newman AB, Simonsick EM, et al. Prevalence and correlates of self-reported medication non-adherence among older adults with coronary heart disease, diabetes mellitus, and/or hypertension. Res Soc Adm Pharm. 2013;9:817-27.

3. Elliott RA. Problems with medication use in the elderly: an Australian perspective. J Pharm Pract Res. 2006;36:58-66.

4. Clinical Medication Review; A Practice Guide (2013) NHS Cumbria (Retrieved on 14 Feb 2014) from: http://www.cumbria. nhs.uk/ProfessionalZone/MedicinesManagement/Guidelines/Med icationReview-PracticeGuide2011.pdf.

5. Pharmaceutical Services Negotiating Committee (2012) MUR service specification (Retrieved on 12 June 2013) from: http:// www.psnc.org.uk/data/files/PharmacyContractandServices/ AdvancedServices/MUR_service_spec_-_Sept_2012.pdf.

6. Pharmaceutical Services Negotiating Committee (2012) and NHS Employers guidance on MURs for pharmacy contractors and their staff (Retrieved on 12 June 2013) from: http://www.psnc.org.uk/ data/files/PharmacyContract/Contract_changes_2011/MUR_gui dance_Sept_2012.pdf.

7. Latif A, Boardman H. Community pharmacists' attitudes towards medicines use reviews and factors affecting the numbers performed. Pharm World Sci. 2008;30:526-35.

8. Livingstone C. Onwards and upwards with target MURs. Pharm J. 2010;284:57-60.

9. The National Health Service Act 2006 Directions (2013) The pharmaceutical services (advanced and enhanced services) England (Retrieved on 12 June 2013) from: http://www.psnc.org.uk/ data/files/PharmacyContract/advanced_service/Pharm_Services_ Adv_Enh_Services_Eng_Directions_2013.pdf.

10. Latif A, Pollock K, Boardman HF. The contribution of the medicines use review (MUR) consultation to counselling practice in community pharmacies. Patient Educ Couns. 2011;83:336-44.

11. Australian Government Department of Health and Aged Care (2006) Guiding principles for medication management in the community, Australian Pharmaceutical Advisory Council 
(Retrieved on 15 June 2013) from: http://www.health.gov.au/ internet/main/publishing.nsf/content/23d9459ecd60326f ca257391001c6cff/\$file/booklet.pdf.

12. Pharmaceutical Society of Australia (2012) guideline for pharmacist providing Meds Check (Retrieved on 17 June 2013) from: http://www.psa.org.au/download/guidelines/3612-medscheckguidelines-c.pdf.

13. DaVanzo J, Dobson A, Koeni L, Book R. Medication therapy management services: a Critical Review. J Am Pharm Assoc. 2005;45:580-7.

14. Thompson CA. State-paid medication therapy management services succeed. Am J Health Syst Pharm. 2008;65:490-8.

15. Lee E, Braund R, Tordoff J. Examining the first year of medicines use review services provided by pharmacists in New Zealand: 2008. N Z Med J. 2009;122:26-35.

16. Kheir N, Fahey M. Pharmacy practice in Qatar: challenges and opportunities. South Med Rev. 2011;4:45-9.

17. Zaidan M, Singh R, Wazaify M, Tahaineh L. Physicians' perceptions, expectations, and experience with pharmacists at Hamad Medical Corporation in Qatar. J Multidiscip Healthc. 2011;4:85-90.

18. Kheir N, Zaidan M, Younes H, El Hajj M, Wilbur K, Jewesson P. Pharmacy education and practice in 13 Middle Eastern countries. Am J Pharm Educ. 2008;72:133.

19. El Hajj MS, Salem S, Mansoor H. Public's attitudes towards community pharmacy in Qatar: a pilot study. Patient Prefer Adherence. 2011;5:405-22.

20. Qatar's National Health Strategy 2011-2016. (Retrieved on 27 June 2013) from: http://www.nhsq.info/app/media/127.

21. Qatar's National Health Strategy (2013) Executive summary update. Supreme Council of Health (Retrieved on 29 June 2013) from: http://nhs.fuegodigital.com/app/media/325.

22. Qatar National Vision 2030 National Health Strategy (Retrieved on 14 February 2014) from: http://www.nhsq.info/about-thestrategy/qatar-national-vision.

23. General Secretariat for Development Planning (2011) National Development Strategy 2011-16 (Retrieved on 26 June 2013) from: http://www.gsdp.gov.qa/gsdp_vision/docs/NDS_EN.pdf.
24. Raosoft sample size calculator. Raosoft, Inc. http://www.raosoft. com/samplesize.html.

25. Pharmaceutical Society of Australia (2011) Guideline for pharmacist providing home medication review (HMR) services (Retrieved on 20 June 2013) from: http://www.psa.org.au/down load/practice-guidelines/home-medicines-review-services.pdf.

26. Edmunds J, Calnan MW. The reprofessionalisation of community pharmacy? An exploration of attitudes to extended roles for community pharmacists amongst pharmacists and general practitioners in the United Kingdom. Soc Sci Med. 2001;53(7): 943-55.

27. Hatah E, Braund R, Duffull S, Tordoff J. General practitioners' perceptions of pharmacists' new services in New Zealand. Int $\mathrm{J}$ Clin Pharm. 2012;34:364-73.

28. Department of Health (DH); London (2003) A vision for pharmacy in the new NHS (Retrieved on 25 June 2013) from: http:// webarchive.nationalarchives.gov.uk/?/www.dh.gov.uk/en/Con sultations/Closedconsultations/DH_4068353.

29. Department of Health (DH); London (2005) Supporting people with long term conditions. An NHS and social care model to support local innovation and integration. (Retrieved on 25 June 2013) from: http://webarchive.nationalarchives.gov.uk/20130107 105354/http://www.dh.gov.uk/prod_consum_dh/groups/dh_digi talassets/@dh/@en/documents/digitalasset/dh_4122574.pdf.

30. Hassell K, Seston EM, Schafheutle EI, Wagner A, Eden M. Workload in community pharmacies in the UK and its impact on patient safety and pharmacists' well-being: a review of the evidence. Health Soc Care Community. 2011;19(6):561-75.

31. Latif A, Pollock K, Boardman HF. Medicines use reviews: a potential resource or lost opportunity for general practice? BMC Fam Pract. 2013;14:57.

32. General Secretariat for Development Planning (2008) Qatar National Vision (QNV) 2030 (Retrieved on 26 June 2013) from: http://www.gsdp.gov.qa/portal/page/portal/gsdp_en/qatar_ national_vision/qnv_2030_document/QNV2030_English_v2.pdf. 